Brief communication

\title{
Ventilation responses to predator odors and conspecific chemical alarm cues in the frillfin goby
}

\author{
Rafaela Torres Pereira ${ }^{a}$, Juliane de Abreu Campos Machado Leutz ${ }^{\mathrm{a}}$, Graziela Valença-Silva ${ }^{\mathrm{a}}$, \\ Leonardo José Gil Barcellos ${ }^{\mathrm{b}, \mathrm{c}}$, Rodrigo Egydio Barreto ${ }^{\mathrm{a}, *}$ \\ a Department of Physiology, Institute of Biosciences of Botucatu, UNESP, CAUNESP, Rubião Jr. s/n, 18618-970, São Paulo State, Brazil

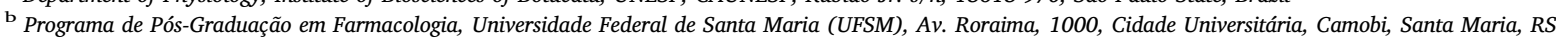 \\ 97105-900, Brazil \\ c Programa de Pós-Graduação em Bioexperimentação, Universidade de Passo Fundo (UPF), Hospital Veterinário, BR 285, Bairro São José, Passo Fundo, RS 99052-900, \\ Brazil
}

\section{A R T I C L E I N F O}

\section{Keywords:}

Alarm substance

Antipredator behavior

Chemical communication

Stress response

Use of public information

\begin{abstract}
A B S T R A C T
The chemical detection of predation risk is direct when based on predator odors, or indirect when an injured conspecific or heterospecific signal it. Physiological adjustments may be necessary in parallel to defensive reactions to cope with an imminent risk. Here, we tested the effects of predator odors and conspecific chemical alarm cues in ventilation response (VR) of frillfin goby, Bathygobius soporator, because this response increases oxygen uptake for supporting behavioral tasks. No VR change was detected in response to odors of predators (catfish) that fed on conspecific, heterospecific fish (tilapia), or were deprived of food and to non-predator (tilapia) that fed chow (non-specific odor control) and odor eluent. The goby's VR, however, increased in response to conspecific alarm cues, but not to heterospecific cues or eluent. Clearly, the VR response in fish depends on the nature of the chemical cue. It is in line with 'threat-sensitive hypothesis' as a chemical cue from an injured prey might mean a foraging predator, whilst the mere presence of a predator odor might not. In addition, because VR can increase, decrease or remains unchanged in response to predation risk in other fish species (including other gobies), we reinforces the species-specific chracteristic of VR responses in fish, regarding the results obtained here for frillfin gobies.
\end{abstract}

\section{Introduction}

The perception of a potential threat imposed by predators is essential for prey survival. The detection of chemical cues that indicates predation risk can be direct, when threat assessment is based on predator odor $[10,24]$. However, it can also be indirect, when a conspecific or heterospecific prey chemically signals the imminent risk [10,24]. In the case of fish, some species have cells located in the epidermis that when damaged by a predator attack release a substance in water (alarm substance) that induces defensive responses in conspecifics [10]. For instance, detection of alarm substance results in changing the priority of responding to relevant environmental stimuli in fish, such as decreased foraging [15] or territorial defense [4,30].

Overall, the behavioral responses in these contexts have been well documented, but the physiological correlates have not. The predation risk (and other stressful situations) increases alertness, and respiratory adjustments can take place. An increase of ventilation rate (VR) might be a way of preparing the body for escaping tasks since a function of the ventilatory system is to supply the body with enough oxygen [12]. In fact, increased VR is a response when fish faces a predation risk based on predator odors (direct cues) in Atlantic salmon Salmo salar [20-22,29] and Nile tilapia Oreochromis niloticus [31] or alarm substances (indirect cues) in Nile tilapia [4,34] and rainbow darters Etheostoma caeruleum [19].

Many predators rely on prey's body movements as stimuli to track them $[7,8]$. Thus, responding to a threat by reducing the VR would increase crypsis, particularly if the prey concomitantly adopts a postural immobility to become less susceptible to detection by predators. In addition, if crypsis fails, a decreased VR would not impair an emergency escape maneuver, because a small escape swimming could be performed anaerobically, requiring no elevation of the VR. In this context, in the presence of a foraging predator, and consequently its odor (direct cue), the strategy of hypoventilation could be a possible action. However, only chemical alarm cues (indirect cues) have been shown to induce hypoventilation in fish, such as in pintado speckled catfish Pseudoplatystoma coruscans [5], piauçu fish Leporinus

\footnotetext{
* Corresponding author

E-mail address: reb@ibb.unesp.br (R.E. Barreto).
} 
macrocephalus [3] and the round goby Neogobius melanostomus [32].

Fish defensive responses in terms of increase or decrease VR could be supposed as a result of the locomotion strategy adopted: dashing/ increased activity or freezing/decreased activity, respectively. However, it is not clear and does not have this positive association between VR and locomotion strategy, because predator odors (Atlantic salmon - [20-22]; Nile tilapia - [31]), as well as alarm substance (Nile tilapia - $[4,34]$ ) can lead to freezing or decreased activity with hyperventilation. Thus, no clear prediction can be made regarding how VR is expected to change with perceived threat.

These disparate observations in VR (hyper- or hypoventilation) point toward the need for better comprehending the effects of chemical cues that indicates predation risk in a greater number of fish species. In this context, we wonder if the cue nature (a direct or indirect indicator of risk) could be an important point. Based on this, the present study evaluates the effects of these direct and indirect chemical cues in ventilation rate of frillfin goby (Bathygobius soporator - locally known as amborê). The frillfin goby is an avid predator of rocky shores and estuaries that consume small fish and crustaceans [26,37]. However, these fish are also predated by larger voracious predators, such as catfish [9]. The frillfin goby is also reactive to alarm substance [6]. Accordingly, the gobies exposed to this stimulus exhibited sheltering and decreased swimming activity.

\section{Materials and methods}

\subsection{Fish and holding conditions}

Specimens of Frillfin goby were collected from the estuary of the Itanhaem River in Itanhaem city, São Paulo state, Brazil. Funnel traps baited with shrimp were used for capturing fish. The traps were sunk into the estuary water near rocks. After a few minutes, the traps were withdrawn from the water and the captured frillfin gobies were gently placed into plastic lidded buckets filled with seawater. This procedure was repeated several times to have a suitable sample size. Constant aeration was provided to bucket water, from the field to the laboratory, using battery-operated air pumps and air stones connected via plastic tubing (nontoxic silicone). No mortality was observed. After collection, the fish (mean length of $\sim 9 \mathrm{~cm}$, standard length of $\sim 7.5 \mathrm{~cm}$ and about 6-7 $\mathrm{g}$ of body mass) were acclimated in plastic stock tanks for 15 days before experimental procedures (12 fish/70 L water; stock density $=1.0 \mathrm{~g} / \mathrm{L}$ of water). The tanks were at constant room temperature $\left(\sim 24{ }^{\circ} \mathrm{C}\right)$ using air conditioning equipment. The water was continuously aerated by air pumps connected to the air stones via nontoxic silicone tubing and with biological and mechanical filtrations. The fish were exposed to natural photoperiod and indirect illumination through lab windows. The fish were fed once a day at $4 \%$ of biomass with commercial feed for bottom-dwelling carnivorous fish [36\% protein; Poytara carnivoros de fundo ${ }^{\circledast}$ (Bottom-dwelling carnivorous fish chow), Poytara LTDA, Araraquara - SP, Brazil].

\subsection{General experimental strategy}

The basic strategy was to evaluate the ventilation rate (VR) of the frillfin gobies, Bathygobius soporator, (Valenciennes, 1837; Fig. S1) before and after exposure to chemical cues. These cues used here have the potential to indicate, directly (predator odors - Experiment 1) or indirectly (alarm cues - Experiment 2), a presence of a threat imposed by a foraging predator. All subjects in both experiments 1 and 2 were experimentally naive, used only in a single trial.

In experiment 1 (prey direct assessment of predator presence), the frillfin goby ( $n=6$ /each condition) was exposed to predator odor (the madamango sea catfish Cathorops spixii). Odor was obtained from predators fed on: 1) conspecific (B. soporator); 2) allopatric heterospecific (Nile tilapia Oreochromis niloticus - to control the specificity of a potential kairomone); or 3) no food (food deprived catfish). In addition, for controlling the specificity of response and lab procedures, response to the odor of: 4) Nile tilapia fed on commercial pellets (nonspecific odor - control kairomone) and 5) artificial seawater without any biological scent (eluent - control) were also assessed.

Experiment 2 (prey indirect assessment of predator presence), we exposed the fish ( $n=10 /$ each condition) to skin extracts of: 1 ) conspecific (alarm substance); 2) heterospecific fish (Nile tilapia - control alarm substance); and 3) extract eluent (distilled water). This chemical cue of a heterospecific fish was used to confirm if the response of frillfin goby to conspecific skin extract was specific or a general response to chemical stimuli from any injured fish (based on [25,27]). In a previous study [6], frillfin goby was not behaviorally reactive (in terms of sheltering and locomotion activity) to heterospecific alarm substance (skin extract of platy fish Xiphophorus maculatus); however, we decided to include a heterospecific control (Nile tilapia skin extract) herein, because we aimed to assess another response variable, the VR, that is a physiological stress variable linked to sympathetic autonomic nervous system. This heterospecific fish, Nile tilapia (Cichlidae), is a phylogenetically distant species from goby species (Gobiidae) and are therefore unlikely to contain the same chemical alarm cues, hence, a suitable heterospecific control fish.

\subsection{Experimental design}

For both experiment 1 and 2 the following experimental protocol was conducted. Specimens of frillfin gobies from the stock population were randomly selected and housed in individual glass aquaria $(23 \mathrm{~L}$; $40 \times 23 \times 25 \mathrm{~cm}$; water volume of $20 \mathrm{~L} ; 1$ fish/aquarium). The fish were acclimated to the experimental aquaria conditions for five days, where they were fed daily as described above, and the leftover food was removed after $1 \mathrm{~h}$. After this period, fish VR was assessed for $3 \mathrm{~min}$ before stimulus presentation (baseline), one time each minute. Next, a chemical stimulus was injected into the experimental aquaria, and fish VR restarted to be assessed $10 \mathrm{~s}$ later of that for an additional $3 \mathrm{~min}$ (post-stimulus period). The mean baseline and post-cue VRs of each singleton were considered for analysis. A methylene blue dye test demonstrated that the colorant was completely spread throughout the aquarium in $\sim 8 \mathrm{~s}$. Behavior recording occurred from $11 \mathrm{~h}$ to $14 \mathrm{~h}$ in a random order defined by raffle.

\subsection{Chemical cues}

The predator (catfish) and non-predator (tilapia) odors were obtained following the procedures that we adapted from Ferrari et al. [13]. Odors from catfish that fed on frillfin goby, tilapia or food deprived ones were obtained from six catfish (mean length of $\sim 22 \mathrm{~cm}$ ) individually housed for six days in 23-L aquaria $(40 \times 23 \times 25 \mathrm{~cm}$; water volume of $20 \mathrm{~L}$ ) with temperature, photoperiod and water conditions similar to the experimental aquarium. Fishes were fed twice during this period (second and fourth day) with prey fillets with skin. On the seventh day, catfish were captured, rinsed with artificial sea water and transferred to other 23-L aquaria, where they were kept for $24 \mathrm{~h}$ in the same conditions described before, but were not fed. After this period, each fish was removed and water was filtered into $50 \mathrm{~mL}$ aliquots and frozen at $-20^{\circ} \mathrm{C}$ until its use is required for the test trial. The non-predator odor was obtained from two Nile tilapia (mean length of $\sim 18 \mathrm{~cm}$, mean weight of $\sim 170 \mathrm{~g}$ ) with the same procedures used to collect predator odor, but Nile tilapia were fed (equivalent of $3 \%$ of body mass $=5 \mathrm{~g}$ ) with commercial fish chow ( $32 \%$ protein). Aliquots of artificial sea water were used as procedures control. The $50-\mathrm{mL}$ aliquots were carefully injected, with an aid of syringe attached to a nontoxic silicon tubing, onto the surface of the water from behind a curtain.

The skin extract was prepared as described by Giaquinto and Volpato [18]. The skin donor fish were sacrificed by cephalic contusion without the use of anesthetics to prevent interference from chemical 
odorants. Twenty-five shallow skin incisions were made on both sides of the animal over the entire body. The fish (one tilapia or a goby of similar size $-\sim 9 \mathrm{~cm}$ ) was placed in a beaker with $200 \mathrm{~mL}$ of chilled distilled water (extract eluent) and carefully swirled for $5 \mathrm{~min}$. The mixture was filtered through $185 \mathrm{~mm}$ filter paper (40 Whatman) to remove any remaining particles. The remaining solution was kept on ice during the experimental procedures. A $10-\mathrm{mL}$ volume of the filtrate was applied to the tank containing the test fish using a syringe [a filtrate volume based on previous observations by Barreto et al. [6]].

\subsection{Ventilation rate quantification}

The VR of frillfin gobies was measured by direct observation [19] and was quantified by measuring the time needed for 20 successive opercular or buccal movements to occur [2]. VR was expressed as opercular beats per minute.

\subsection{Experimental aquaria conditions}

The experimental aquaria were equipped with air stones, each of which was connected to an air pump by nontoxic silicone tubing for constant aeration. Artificial sea water was used to avoid any environmental scent that might be present in natural seawater. The water temperature was $\sim 24^{\circ} \mathrm{C}$, the $\mathrm{pH}$ was $\sim 8.0$, specific gravity $\sim 1024$ and salinity $\sim 33.5 \mathrm{ppt}$. The concentrations of nitrite and ammonia were lower than 0.5 and $0.01 \mathrm{mg} / \mathrm{L}$, respectively. The photoperiod and illumination were natural.

\subsection{Data analyses}

The data's normality and homoscedasticity were assessed by using the Shapiro-Wilk W test and Levene's test, respectively. The data satisfied these premises for the use of parametric tests. The data of experiments 1 and 2 were analyzed using a 2-way mixed ANOVA [a between-subjects categorical predictor (chemical cues) and a withinsubject repeated measures (time - before and after cue presentation) ANOVA], followed by a Duncan test when necessary. The VR was the dependent variable in these models. The statistical results were considered significant when $\mathrm{p}<0.05$.

\section{Results}

In experiment 1 , goby VR was assessed before and after exposure to predator odors (Fig. 1). No effects of the chemical cue $\left(\mathrm{F}_{(4 ; 25)}=0.95\right.$; $\mathrm{p}=0.45)$, time $\left(\mathrm{F}_{(1 ; 25)}=0.12 ; \mathrm{p}=0.73\right)$ or interaction between time and chemical cue $\left(\mathrm{F}_{(4 ; 25)}=0.54 ; \mathrm{p}=0.70\right)$ were found. However, in experiment 2, wherein fish VR were quantified before and after exposure to conspecific skin extract, ANOVA revealed a significant interaction between time and chemical cue $\left(\mathrm{F}_{(2 ; 27)}=21.18\right.$; $\mathrm{p}=0.000003$; Fig. 2), indicating that chemical cue and time conjointly induced an effect in VR (isolated effects of the categorical factors were: chemical cue, $\mathrm{F}_{(2 ; 27)}=2.55 ; \mathrm{p}=0.097 ;$ and time $\mathrm{F}_{(1 ; 27)}=15.06$; $\mathrm{p}=0.0006)$. The found interaction indicates that conspecific skin extract induced a significant increase in frillfin goby's VR compared to baseline levels. This effect was not observed for goby exposed to heterospecific skin extract or extract eluent. Moreover, post-stimulus VR of gobies were significantly higher for fish exposed to conspecific cue than VR of those fish exposed to heterospecific cues or extract eluent.

The ANOVA also showed that, before stimuli presentation, in both experiment 1 and 2, the mean basal VRs were statistically indistinguishable among groups. This analysis indicates that fish started from similar resting VR.

\section{Discussion}

In this study, physiological responses of frillfin goby to threatening

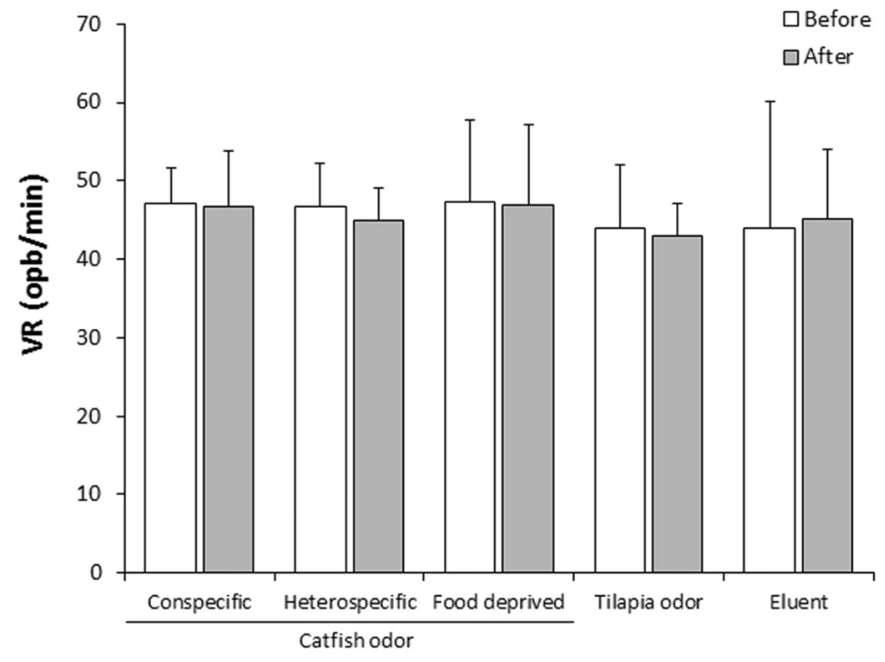

Fig. 1. Ventilation rate of frillfin goby Bathygobius soporator exposed to predator odors. Mean values ( $\pm \mathrm{SD}$; $\mathrm{N}=6$ fish each condition). ANOVA showed no effects of the chemical cue $\left(\mathrm{F}_{(4 ; 25)}=0.95 ; \mathrm{p}=0.45\right)$, time $\left(\mathrm{F}_{(1 ; 25)}=0.12 ; \mathrm{p}=0.73\right)$ or interaction between time and chemical cue $\left(\mathrm{F}_{(4 ; 25)}=0.54 ; \mathrm{p}=0.70\right)$.

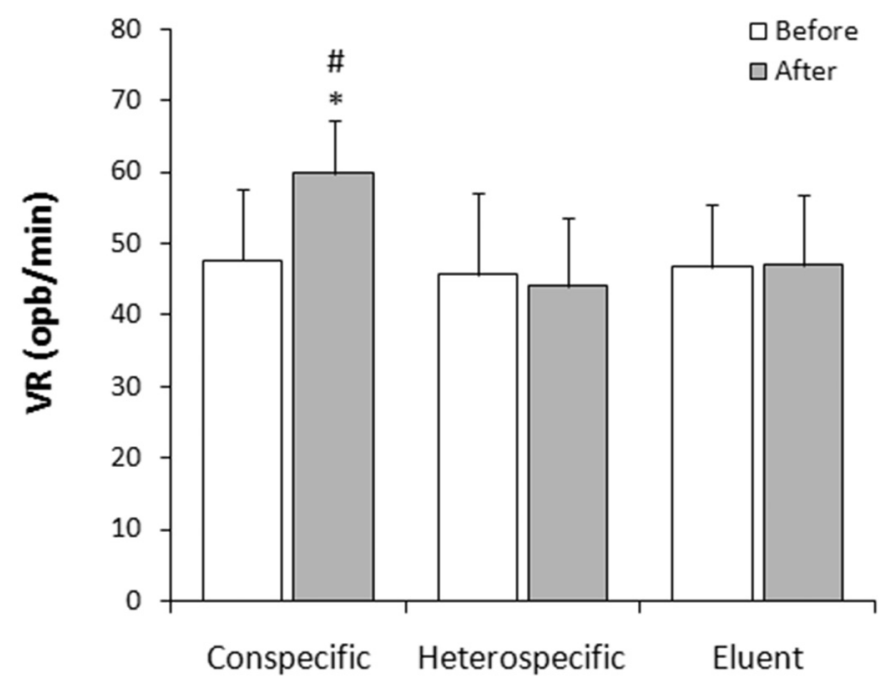

Fig. 2. Ventilation rate (VR) of frillfin goby Bathygobius soporator exposed to skin extracts. Mean values ( $\pm \mathrm{SD} ; \mathrm{N}=10$ fish each condition). ANOVA revealed a significant interaction between time and chemical cues $\left(\mathrm{F}_{(2 ; 27)}=21.18 ; \mathrm{p}=0.000003\right)$. * indicates a significant increase in frillfin goby's VR compared to baseline levels for conspecific chemical cues condition. \# indicates that post-stimulus VR of fish exposed to conspecific chemical alarm cue is higher than the other post-stimulus VRs. Baseline values of VR were statistically indistinguishable.

chemical cues are dependent on cue type. Herein, goby exposed to conspecific chemical alarm cue (indirect cue) increased the VR, whereas predator odor (direct cue) induced no change in VR. Thus, our data indicates that the nature of the cue (direct or indirect cues) is a factor influencing the VR response profile. Reinforcing this possibility, zebrafish (Danio rerio) retreated or were non-reactive in response to water conditioned with cues emanating from stressed conspecifics exposed to different types of stressors [1]. Moreover, considering that the round goby ( $N$. melanostomus - [32]), therefore a phylogenetically close fish to frillfin goby, showed a decreased VR in response to conspecific alarm cues, we suggest a species-specific quality of VR response when fish are perceiving a potential predator threat.

In aquatic environments, information about predation risk often occurs via chemical signals [40]. Predator-prey interactions produce chemicals information indicating the proximity and magnitude of a predation threat and this information can result in different behavioral defensive responses [10]. For instance, the chemical cues of the 
conspecific skin extract induce a change in prey fish priority to respond to relevant factors (stimulus filtering), decreased foraging [16] or territorial defense [4]. Here, the defensive strategy regarding respiratory adjustment of the frillfin goby consisted of evaluating the cue from an injured conspecific and display a stress response (increased VR). This physiological regulation increases oxygen uptake, supplying the body with enough oxygen for any behavioral task performed aerobically [12]. The presence of an injured conspecific prey clearly indicates a nearby presence of a predator that is highly motivated to eat, hence, a risky situation. Public chemical information of predation risk can be provided by neighbors and induce defensive reactions [40]. This strategy of increase VR in frillfin goby induced by chemical alarm cue obtained via publicly available information is plausible in this species because they live in close proximity to conspecifics [28]. Thus, the individual that detect and respond to the chemical cues of the conspecific have more chance of survival.

Prey can detect the threat by a predator odor (kairomone) or odor associated with a prey in the digestive tract of the predator (dietary cues). However, in this study, no difference in VR took place after exposure to predator odor fed with conspecific or heterospecific compared to basal levels of VR. It is known that prey can get risk information evaluating the concentration of chemical signal in water [10]. High concentrations may indicate an imminent risk of predation [10,14]. Thus, it is plausible to think that skin extract is a more concentrated chemical signal, indicating more readily that there may be a predator motivated to eat and to increase VR enable the necessary adjustments to the animal in the case of an emergency defensive reaction. Moreover, in this context, the absence of response to the presence of catfish odor is consistent with the predictions of the threat-sensitive hypothesis. The threat-sensitivity hypothesis predicts that prey animals alter their intensity of predator defensive responses according to the magnitude of the threat, representing, therefore, an adaptive advantage for avoiding unnecessary time and energy loss [23]. To respond to the mere presence of a catfish odor could lead to the execution of many unnecessary defensive actions, a condition that would be highly energy expensive for the gobies. Hence, prey might decrease their level of antipredator behavior and redirect their efforts to other behaviors that also contribute for increasing survival (e.g. foraging and other resources acquisition [33]).

The presence of predator odor may indicate the presence of predator, but not necessarily an imminent risk, because it could not be a foraging predator, therefore, it could explain the absence of VR changes in response to predator odors. However, to increase VR due to the presence of chemical cues of injured conspecific indicate a more immediate risk, because suggest the presence of a foraging predator (e.g. one that struck and injured a conspecific goby). Since prey responses to predators have costs (e.g. metabolic costs - [11]), unnecessary and constant defensive reactions may represent high energy expenditure and time consumed in an needless activity in the case of frequent responses to non-foraging predators. At same time, a presence of a nonforaging predator is not a threat until it initiates foraging activities. Thus, considering the absence of response to predator odors, a possibility may be related to frillfin gobies to live in dense assemblages (groups from 1 to 40 fish into an area of $4 \mathrm{~m}^{2}-$ [28]), characterizing a potential dilution of predation risk. In fact, a dilution of predation risk is effective when prey are exposed to a foraging predator because for any one predator attack, the larger the group of prey animals, the smaller the chance that any particular individual will be the victim [17]. Moreover, frillfin goby changes body color (e.g. from pale to dark body) according to background [36] and, frequently, stay inside shelters (e.g. rock crevices), that represents some ways of being safe from predator attacks. Thus, to avoid high costs of frequent unnecessary defensive responses due to the mere presence of a predator, defensive reactions occur when there is a more clear indicator of foraging predator (alarm chemical cue released by injured conspecific) and other factor might improve safety against predator in frillfin goby (e.g. dilution effect, sheltering and camouflage) when a foraging predator is not clearly detectable.

Alternatively to the above statements, the chemically mediated perception of risk by prey fish was recently shown to vary as a function of the amount of prey biomass consumed by a predator [39]. Thus, the absence of response to predator odors herein could be explained by a less concentrated scent, although we followed a successful protocol to produce a kairomone [13]. However, it must be clarified in future studies, especially because prey can be unreactive to predator odor and may suffer no influence of predator diet [35] and diet-derived cues could be specific enough and would result in lots of spurious reactions [38].

Supplementary data to this article can be found online at http://dx. doi.org/10.1016/j.physbeh.2017.06.023.

\section{Acknowledgement}

This study was financially supported by the Fundaçãopara o Desenvolvimento da UNESP - FUNDUNESP (Process 00017/08).

\section{References}

[1] M.S. Abreu, A.C.V. Giacomini, D. Gusso, G. Koakoski, T.A. Oliveira, A. Marqueze, R.E. Barreto, L.J.G. Barcellos, Behavioral responses of zebrafish depend on the type of threatening chemical cues, J. Comp. Physiol. A Neuroethol. Sens. Neural Behav. Physiol. 202 (2016) 895-901.

[2] C.M. Alvarenga, G.L. Volpato, Agonistic profile and metabolism in alevins of the Nile tilapia, Physiol. Behav. 57 (1995) 75-80.

[3] A. Barbosa-Júnior, F.L. Alves, A.S.F. Pereira, L.M. Ide, A. Hoffmann, Behavioral characterization of the alarm reaction and anxiolytic-like effect of acute treatment with fluoxetine in piauç fish, Physiol. Behav 105 (2012) 784-790.

[4] R.E. Barreto, A. Barbosa-Junior, A.C.C. Giassi, A. Hoffmann, The club cell and behavioural and physiological responses to chemical alarm cues in the Nile tilapia, Mar. Freshw. Behav. Physiol. 43 (2010) 75-81.

[5] R.E. Barreto, A.J. Barbosa, A. Hoffmann, Ventilatory responses to skin extract in catfish, Aquat. Biol. 15 (2012) 205-214.

[6] R.E. Barreto, A. Barbosa-Junior, E.C. Urbinati, A. Hofmann, Cortisol influences the antipredator behavior induced by chemical alarm cues in the frillfin goby, Horm. Behav. 65 (2014) 394-400.

[7] M.T. Burrows, R.N. Gibson, L. Robb, C.A. Comely, Temporal patterns of movement in juvenile flatfishes and their predators: underwater television observations, J. Exp. Mar. Biol. Ecol. 177 (1994) 251-268.

[8] M.T. Burrows, R.N. Gibson, The effects of food, predation risk and endogenous rhythmicity on the behavior of juvenile plaice, Pleuronectes platessa L, Anim. Behav. 50 (1995) 41-52.

[9] A. Chalom, E.Y. Muto, L.S.H. Soares, Variabilidade trófica na alimentação do bagreamarelo Cathorops spixii (Agassiz, 1829) no litoral do estado de São Paulo, in: E.S. Braga (Ed.), Oceanografia e mudanças globais, Instituto Oceanográfico da Universidade de São Paulo/Brasil, São Paulo, 2008, pp. 257-272.

[10] D.P. Chivers, R.J.F. Smith, Chemical alarm signaling in aquatic predator-prey systems: a review and prospectus, Ecoscience 5 (1998) 38-352.

[11] S.J. Cooke, J. Steinmetz, J.F. Degner, E.C. Grant, D.P. Philipp, Metabolic fright responses of different-sized largemouth bass (Micropterus salmoides) to two avian predators show variations in nonlethal energetic costs, Can. J. Zool. 81 (2003) 699-709.

[12] M.N. Fernandes, F.T. Rantin, Relationships between oxygen availability and metabolic cost of breathing in Nile tilapia (Oreochromis niloticus): aquacultural consequences, Aquaculture 127 (1994) 339-346.

[13] M.C.O. Ferrari, F. Messier, D.P. Chivers, The nose knows: minnows determine predator proximity and density through detection of predator odors, Anim. Behav. 72 (2006) 927-932.

[14] M.C.O. Ferrari, G.E. Brown, F. Messier, D.P. Chivers, Threat-sensitive generalization of predator recognition by larval amphibians, Behav. Ecol. Sociobiol. 63 (2009) 1369-1375.

[15] M.C.O. Ferrari, R.P. Manassa, D.L. Dixson, P.L. Munday, M.I. McCormick, M.G. Meekan, A. Sih, D.P. Chivers, Effects of ocean acidification on learning in coral reef fishes, PLoS One 7 (2) (2012) e31478, http://dx.doi.org/10.1371/journal. pone.0031478.

[16] P.E. Foam, R.S. Mirza, D.P. Chivers, G.E. Brown, Juvenile convict cichlids (Archocentrus nigrofasciatus) allocate foraging and antipredatorbehaviour in response to temporal variation in predation risk, Behaviour 142 (2005) 129-144.

[17] W.A. Foster, J.E. Treherne, Evidence for the dilution effect in selfish herd from fish predation on a marine insect, Nature 293 (1981) 466-467.

[18] P.C. Giaquinto, G.L. Volpato, Hunger suppresses the onset and the freezing component of the antipredator response to conspecific skin extract in speckled catfish, Behaviour 138 (2001) 1205-1214.

[19] A.K. Gibson, A. Mathis, Opercular beat rate for rainbow darters Etheostoma caeruleum exposed to chemical stimuli from conspecific and heterospecific fishes, J. Fish Biol. 69 (2006) 224-232. 
[20] L.A. Hawkins, A.E. Magurran, J.D. Armstrong, Innate predator recognition in newly-hatched Atlantic Salmon, Behaviour 141 (2004) 1249-1262.

[21] L.A. Hawkins, J.D. Armstrong, A.E. Magurran, Predator-induced hyperventilation in wild and hatchery Atlantic salmon fry, J. Fish Biol. 65 (2004) 88-100.

[22] L.A. Hawkins, A.E. Magurran, J.D. Armstrong, Innate abilities to distinguish be tween predator species and cue concentration in Atlantic salmon, Anim. Behav. 73 (2007) 1051-1057.

[23] G.S. Helfman, Threat-sensitive predator avoidance in damselfish-trumpetfish interactions, Behav. Ecol. Sociobiol. 24 (1989) 47-58.

[24] L.B. Kats, L.M. Dill, The scent of death: chemosensory assessment of predation risk by prey animals, Ecoscience 5 (1998) 361-394.

[25] J.K. Larson, M.I. McCormick, The role of chemical alarm signals in facilitating learned recognition of novel chemical cues in a coral reef fish, Anim. Behav. 69 (2005) 51-57.

[26] P.R.D. Lopes, J.T. Oliveira-Silva, Alimentação de Bathygobius soporator (Valenciennes, 1837) (Actinopterygii: Teleostei: Gobiidae) na localidade de Cacha Pregos (Ilha de Itaparica), Bahia, Brasil, Biotemas 11 (1998) 81-92.

[27] R.P. Manassa, D.L. Dixson, M.I. McCormick, D.P. Chivers, Coral reef incorporate multiple sources of visual and chemical information to mediate predation risk, Anim. Behav. 86 (2013) 717-722.

[28] L. de F. Mendes, Natural history focus blennies and gobies behaviour (Actinopterygii, Blennioidei, Gobioidei) from Fernando de Noronha Archipelago, Rev. Bras. Zool. 23 (2006) 817-823.

[29] N.B. Metcalfe, F.A. Huntingford, J.E. Thorpe, The influence of predation risk on the feeding motivation and foraging strategy of juvenile Atlantic salmon, Anim. Behav. 35 (1987) 901-911.
[30] D. Meuthen, S.A. Baldauf, T.C.M. Bakker, T. Thünken, Conspecific alarm cues affect interspecific aggression in cichlid fishes, Hydrobiologia 767 (2015) 1-13.

[31] C.A. Miyai, F.H.C. Sanches, C.F. Pinho-Neto, R.E. Barreto, Effects of predator odour on antipredator responses of Nile tilapia, Physiol. Behav. 165 (2016) 22-27.

[32] Ž. Pūtys, L. Ložys, V. Būda, Respiratory response to the chemical cues of injured conspecifics and histology of skin in round goby, Neogobius melanomostus (Actinopterygii: Perciformes: Gobiidae), ActaIchthyol. Piscat. 45 (2015) 411-415.

[33] O. Roux, A. Diabate, F. Simard, Divergence in threat sensitivity among aquatic larvae of cryptic mosquito species, J. Anim. Ecol. 83 (2014) 702-711.

[34] F.H.C. Sanches, C.A. Miyai, C.F. Pinho-Neto, R.E. Barreto, Stress responses to chemical alarm cues in Nile tilapia, Phys. Behav. 149 (2015) 8-13.

[35] A.E. Scherer, D.L. Smee, A review of predator diet effects on prey defensive responses, Chemoecology (2016), http://dx.doi.org/10.1007/s00049-016-0208-y.

[36] W.N. Tavolga, Pattern variability among populations of the gobiid fish Bathygobius soporator, Copeia 1950 (1950) 182-194.

[37] L. Tomida, J.T. Lee, R.E. Barreto, Stomach fullness modulates a visually-based preysize choice in a predator fish, the frillfin goby Bathygobius saporator, Zoology (Jena) 115 (2012) 283-288.

[38] M. Weissburg, D.L. Smee, M.C. Ferner, The sensory ecology of nonconsumptive predator effects, Am. Nat. 184 (2014) 141-157.

[39] M. Weissburg, J. Beauvais, The smell of success: the amount of prey consumed by predators determines the strength and range of cascading non-consumptive effects, PeerJ 3 (2015) e1426, http://dx.doi.org/10.7717/peerj.1426.

[40] B.D. Wisenden, D.P. Chivers, The role of public chemical information in antipredator behaviour, in: F. Ladich, S.P. Collins, P. Moller, B.G. Kapoor (Eds.), Fish Chemoreception, Science Publisher, Enfield, 2006, pp. 259-278. 